\title{
PESQUISA-AÇÃO EM UMA DISCIPLINA A DISTÂNCIA DE INTRODUÇÃO À COMPUTAÇÃO EM UM CURSO PRESENCIAL
}

\section{INVESTIGACIÓN-ACCIÓN EN UNA DISCIPLINA A DISTANCIA DE INTRODUCCIÓN A LA COMPUTACIÓN EN UN CURSO PRESENCIAL}

\section{ACTION RESEARCH IN A DISTANCE DISCIPLINE OF INTRODUCTION TO COMPUTING IN A CLASSROOM COURSE}

Márcio Magera Conceição ${ }^{1}$ Ricardo Shitsuka², Dorlivete Moreira Shitsuka³ ${ }^{3}$ Caleb David Willy Moreira Shitsuka ${ }^{4}$

Submetido em: 13/04/2019

Aprovado em: 24/04/2020

\section{RESUMO}

Os cursos superiores presenciais de Licenciatura no Brasil podem conter até $40 \%$ de disciplinas a distância. Essas pressupõem o emprego de um ambiente virtual e a separação física entre quem ensina e os que aprendem e há estudantes que apresentam dificuldades em relação à modalidade da Educação a Distância (EAD). Acredita-se que por meio da forma de trabalho do tutor, torna-se possível melhorar a satisfação do aluno nas disciplinas EAD. O objetivo deste artigo é apresentar um estudo no qual os alunos de uma disciplina inicial de um curso inicialmente apresentam dificuldades de participação e engajamento na disciplina de introdução à computação. Realiza-se um trabalho de pesquisa-ação por meio do qual se ouvem as dificuldades dos alunos e realizam-se propostas conjuntas para o trabalho tutoral. Passa-se a trabalhar nos fóruns da disciplina com o emprego de cores e letras diferentes para cada participante, padronizando desta forma a participação de cada aluno do curso. Observa-se por meio das notas e de uma coleta de informações no final do período que os alunos melhoram seu desempenho na disciplina, participação e engajamento no curso.

PALAVRAS-CHAVE: Pesquisa participativa. Trabalho colaborativo. Informática na educação. Tecnologias educacionais.

\section{RESUMEN}

Los cursos superiores presenciales de Licenciatura en Brasil pueden contener hasta un $40 \%$ de disciplinas a distan-

\footnotetext{
${ }^{1}$ Pós-Doutor em Ciências Sociais pela Unicamp. Doutorado em Ciências Sociais pela PUC-SP. Doutorado em Administração pela Florida Christian University. http://lattes.cnpq.br/2025008893443488. Correio eletrônico: magera1963@gmail.com.

${ }^{2}$ Doutor em Ensino de Ciências na Universidade Cruzeiro do Sul. Mestre em Engenharia pela EPUSP. Pós-graduação em Tecnologia, Formação de Professores e Sociedade na UNIFEI. Pós-graduação em Tecnologias Educacionais pela FAAP. Pósgraduação em Design Instrucional para EAD pela UNIFEI. Graduação em Pedagogia. Graduação em Odontologia. Graduação em Licenciatura em Computação. Graduação em Engenharia. http://orcid.org/0000-0003-2630-1541. Correio eletrônico: ricardoshitsuka@unifei.edu.br

${ }^{3}$ Professora na UNIFMU/Laureate University. Tutora de EAD no PIGEAD/LANTE/UFF. Mestre em Ensino pela UNICSUL. Pesquisadora no Grupo de Pesquisas MEAC. http://orcid.org/0000-0002-3282-4843. Correio eletrônico: dorlivetems@gmail.com ${ }^{4}$ Doutor em Ciências da Saúde. Mestre em Ciências da Saúde. Especialista em Educação a Distância. http://lattes.cnpq. br/1001992199775837. Correio eletrônico: cashitsuka@gmail.com
} 
cia. Estas presupone el empleo de un ambiente virtual y la separación física entre quien enseña y los que aprenden y hay estudiantes que presentan dificultades en relación a la modalidad de la Educación a Distancia (EAD). Se cree que por medio de la forma de trabajo del tutor, se hace posible mejorar la satisfacción del alumno en las asignaturas EAD. El objetivo de este artículo es presentar un estudio en el cual los alumnos de una disciplina inicial de un curso inicialmente presentan dificultades de participación y compromiso en la disciplina de introducción a la computación. Se realiza un trabajo de investigación-acción por medio del cual se oye las dificultades de los alumnos y se realizan propuestas conjuntas para el trabajo tutoral. Se pasa a trabajar en los foros de la disciplina con el empleo de colores y letras diferentes para cada participante, estandarizando de esta forma la participación de cada alumno del curso. Se observa por medio de las notas y de una recolección de informaciones al final del período que los alumnos mejoran su desempeño en la disciplina, participación y compromiso en el curso.

PALABRAS CLAVE: Investigación participativa. Trabajo colaborativo. Informática en la Educación. Tecnologías educativas.

\section{ABSTRACT}

Bachelor's degree courses in Brazil can contain up to $40 \%$ of distance learning courses. These presuppose the use of a virtual environment and the physical separation between those who teach and those who learn and there are students who present difficulties in relation to the mode of distance education. It is believed that through the form of work of the tutor, it becomes possible to improve student satisfaction in the EAD discipline. The aim of this article is to present a study in which the students of an initial discipline of a course initially present difficulties of participation and engagement in the subject of introduction to computing. A work of action research is carried out through which the students' difficulties are heard and joint proposals are made for the tutorial work. It is used in the disciplinary forums with the use of different colors and letters for each participant, thus standardizing the participation of each student of the course. It is observed through the notes and an information collection at the end of the period that the students improve their performance in the discipline, participation and engagement in the course.

KEYWORDS: Participatory research. Collaborative work. Informatics in education. Educational technologies. 


\section{INTRODUÇÃO}

A Educação a Distância (EAD) continua avançando na Educação Superior brasileira. Mirshawka e Mirshawka (2002) consideram que a modalidade mista, blended ou semipresencial era uma tendência na educação e, ao longo dos anos verifica-se que isso tem ocorrido, inicialmente, Brasil (2016) regulamenta os $20 \%$ de EAD nos cursos presenciais que tenham algum curso já reconhecido e, Brasil (2018) permite até $40 \%$ de EAD em cursos presenciais como é o caso dos cursos de Licenciatura que desta forma, vão possibilitando que os alunos passem menos horas em sala de aula.

Em um curso cujas aulas ocupam cinco dias da semana, os $40 \%$ poderiam equivaler a tirar dois dias de aula presencial que poderiam ser tralhados a distância em Ambientes Virtuais de Aprendizagem (AVA) e o desenvolvimento de trabalhos voltados para o entendimento e melhoria das disciplinas a distância torna-se importante para alunos, tutores, professores e instituições interessadas em melhorar a educação e o aprendizado.

Nos componentes curriculares EAD existem estudantes que apresentam dificuldades iniciais de adaptação uma vez que elas exigem momentos de autodidatismo, pesquisa e construção ativa do conhecimento por parte do aluno que muitas vezes, é acostumado aos modelos tradicionais nos quais o professor explica a matéria e o aluno ouve passivamente ou quando muito copia o conteúdo em seu caderno.

Acredita-se que muitas dificuldades de aprendizagem na EAD podem ser superadas por meio do trabalho do tutor de EAD que é a pessoa que faz a ligação entre as atividades, a participação do estudante e o aprendizado do conteúdo. O objetivo deste artigo é apresentar um estudo no qual os alunos de uma disciplina apresentam dificuldades de participação no fórum e de engajamento na disciplina e esta situação é transformada por meio da forma de trabalho do tutor.

Nas linhas seguintes aborda-se a questão da Dependência das Ferramentas do Ambientes Virtuais na Qualidade do Trabalho de seus Participantes. A seguir fala-se sobre As Dificuldades de Aprendizado dos Alunos em Disciplinas a Distância. O passo seguinte apresenta metodologia da pesquisa-ação participativa que foi empregada para a busca de soluções para problemas no ambiente educacional. Após a metodologia apresenta- se o estudo com suas discussões e as considerações finais.

\section{DEPENDÊNCIA DAS FERRAMENTAS DOS AMBIENTES VIRTUAIS NA QUALIDADE DO TRABALHO DE SEUS PARTICIPANTES}

A qualidade das participações, dos trabalhos realizados pelos alunos e da aprendizagem, está relacionada à motivação dos alunos e tutores. Campos (2014) considera que a motivação é uma "força" que surge internamente aos alunos como resposta a incentivos que são externos. Compartilhamos está colocação da autora e que nos AVA os incentivos têm que acontecer nas ferramentas e por meio da participação dos atores.

As ferramentas existentes, atualmente, nos ambientes virtuais de aprendizagem, entre as quais se incluem: fórum, chat, glossário, wiki, envio de textos, envio de vídeos, etc. dependem do engajamento dos atores envolvidos no processo educacional.

Para Risemberg, Shitsuka e Tavares (2015) em um estudo comparando as participações de estudantes de Administração de Empresas, Pedagogia e Tecnologia, consideram que há diferenças de padrão de participação.

Consideramos que a formação dos participantes pode influenciar, por exemplo na participação nas ferramentas dos AVA e neste sentido, os alunos de Pedagogia sabem que terão que lidar com pessoas e por isso, terão que comunicar, falar com seus futuros alunos e frequentar ambientes nos quais terão que participar, emitir opiniões e influenciar pessoas e desta forma, vão se preparando ao longo do curso para realizar as intervenções.

Observa-se nas ferramentas mencionadas que a participação de alunos, tutores e professores depende fortemente da motivação, da interação e da qualidade do trabalho realizado por estes participantes.

Em outro estudo realizado em uma turma de capacitação para formação de tutores EAD para ministrar a disciplina de Libras, Shitsuka e Shitsuka (2015) verificaram que no ambiente virtual havia uma relação entre a qualidade da participação dos atores e a qualidade do aprendizado. De fato, as ferramentas são "frias" e dependem dos atores que vão inserir o conteúdo nelas.

Para Silva, Shitsuka e Paschoal (2014) a afetividade nas participações que se manifesta, por 
exemplo, por meio da dialogicidade, pode servir como fator incentivador para que ocorra a participação dos alunos e para que ocorra o aprendizado de modo facilitado. Quando os alunos estão em disciplinas a distância, podem ocorrer dificuldades como se observa no item a seguir.

Tenório, Costa e Tenório (2016) consideram que a forma de atuação empática por parte do tutor pode se constituir em um incentivo para que os alunos de educação a distância se envolvam com o curso e diminuam suas dificuldades na aprendizagem. A empatia pode ser um fator importante para a participação do aluno que desta forma se sente "aceito" pelo tutor e grupo. Nem todos os tutores trazem a empatia como uma característica nata e muitos precisam ser preparados ou sensibilizados para atuar de modo empático e melhorar a participação e atuação do aluno no curso.

Palloff e Pratt (2002) quando estudam as comunidades virtuais nos cursos EAD, consideram que os princípios nesta modalidade educacional são de uma forma mais ativa e colaborativa de aprendizagem, com a diferença que para que haja sucesso na EAD, tornase interessante que exista o sentido pertencimento e participação na comunidade virtual.

As comunidades virtuais são semelhantes às redes sociais nas quais as pessoas participam muitas vezes por prazer em se comunicar uns com os outros, outras vezes, encontram amigos de tempos passados que não se viam há anos e ocorre um aspecto de interação entre as pessoas de modo semelhante ao considerado por Vygotsky (2008), ou seja, de modo histórico social e isso faz com que ocorra uma participação maior e continuada e que favorece a aprendizagem de modo social.

\section{DIFICULDADES DE APRENDIZAGEM DE ALUNOS DE DISCIPLINAS A DISTÂNCIA}

As disciplinas EAD dos cursos presenciais seguem os princípios gerais da EAD: tem que ter a infraestrutura, tutores, documentação estabelecendo as formas de trabalho e avaliação. Em termos de profissionais, para Brasil (2016), a Portaria 1134 instrui no seu artigo segundo que a oferta das disciplinas previstas no art. $1^{\circ}$ "deverá incluir métodos e práticas de ensino-aprendizagem que incorporem o uso integrado de tecnologias de informação e comunicação para a realização dos objetivos pedagógicos, bem como prever encontros presenciais e atividades de tutoria".

Verifica-se que a Lei exige o emprego das Tecnologias de Informação e Comunicação (TIC) que se traduz na necessidade de uma infraestrutura tecnológica de hardware e software adequados, bem como, em sequência, o emprego de encontros presenciais e tutoria. Complementando, o parágrafo único pede que os tutores sejam "profissionais da educação com formação na área do curso e qualificados em nível compatível ao previsto no projeto pedagógico".

Interpretamos que os profissionais mencionados são os graduados em algum curso das Ciências da Educação que incluem a Pedagogia e as Licenciaturas e que estes profissionais também tenham formação na área do curso e que sejam preparados de modo compatível com as exigências do projeto pedagógico do curso presencial que tenha as disciplinas a distância.

Nem sempre as instituições contam com profissionais que atendam aos quesitos mencionados: ora o profissional não conta com a formação exigida tanto em ciência da educação como na formação na área do curso como mencionado ou o atendimento ao projeto pedagógico do curso em foco e desta forma, nem sempre realizam o trabalho mais completo na comunicação com os alunos resultando em uma motivação menor que a esperada.

Ferreira e Silva (2009) consideram que para o aluno da EAD alcançar o sucesso é necessário que ele supere o desafio $\urcorner$ de estudar sozinho e, neste sentido, tem que adquirir habilidades e competências para alcançar a autonomia no seu aprendizado.

A falta em adquirir a autonomia pode gerar a evasão escolar. Para Netto, Guidotti e Santos (2012) uma das causas importantes de evasão na EAD é a falta de adaptação ao método dessa modalidade e, uma forma de superação é por meio da flexibilidade tanto por parte dos alunos quanto também do tutor ou professor. Este fato é confirmado por Boghi, Shitsuka e Shitsuka (2019) que consideram que uma das formas de se minimizar esta evasão pode ser por meio de terapias alternativas que permitam as pessoas se sentirem ouvidas e as ajudem a se organizar para enfrentar os desafios existentes nos cursos a distância.

A tentativa de superação das dificuldades muitas vezes pode ser realizada por um trabalho conjunto entre os alunos e a tutoria que leve a algum tipo de trabalho diferenciado com os alunos com dificuldades e um 
exemplo vem com Shitsuka et al. que afirmam:

Mesmo com as facilidades que existem nos tempos atuais, ainda há o caso de pessoas que possuem dificculdades, sejam por problemas cognitivos ou por alguma diาficuldade na formação geral, e, na medida do possível, cabe ao tutor de EaD identiาficar tais situações e procurar fazer um trabalho diferenciado para não perder esses alunos (SHITSUKA, SHITSUKA e BOGHI, 2018, p.8).

Um aluno da EAD tendo observado que está com dificuldades, deve entrar em contato com o professor e torna-se interessante que este busque compreender as dificuldades e procurar ajudar o aluno a superá-las. Um caminho que leve a recuperação do aluno e se evite a ocorrência da evasão escolar, como já se apontou na seção anterior pode ser se iniciar por meio da afetividade manifestada principalmente pela dialogicidade, empatia e a busca pela integração do aluno ao grupo.

No caso dos cursos ou disciplinas que sejam na modalidade EAD, o passo seguinte pode ser 0 agendamento de visita do aluno ao polo para minimizar dificuldades no contato direto com o tutor (este trabalho pode ser realizado também alternativamente, por meio de contato telefônico ou por atendimento online e real time) e em seguida a elaboração e proposição de atividades ou trabalhos alternativos ou de recuperação ao longo do processo, ou pela realização de algum trabalho diferenciado nos encontros presenciais da disciplina.

\section{METODOLOGIA E ANÁLISE}

Metodologia é o caminho para se atingir o objetivo. Esse objetivo vem a partir de um problema como consideram Pereira et al. (2018). Neste estudo, o problema é a dificuldade de aprendizagem em alunos de uma disciplina EAD de Introdução à Computação em um curso presencial.

A busca pela resolução de um problema em ambiente escolar pode vir por meio de um trabalho de pesquisa seguido de alguma ação. Thiollent (2011) utiliza a pesquisa-ação participativa em ambientes de trabalho levando em conta que esta pode ser uma forma eficiente de se encontrar soluções para problemas envolvendo os participantes. No caso do emprego deste tipo de pesquisa nos ambientes escolares, Pereira et al. afirmam que:

\section{Esse tipo de enfoque é particularmente importante na formação dos professores, uma vez que o tempo nos bancos escolares em cursos de licenciatura ou outros de bacharelado frequentemente se mostram insuficientes para se trabalhar todos os aspectos possíveis, que podem ocorrer em situações práticas do cotidiano escolar, uma vez que a prática do cotidiano é muito mais rica em possibilidades (PEREIRA et al., 2018, p.48).}

$\mathrm{Na}$ pesquisa-ação ao mesmo tempo em que o pesquisador pode estar envolvido na resolução do problema, esta forma de pesquisa também enriquece a experiência do professor e dos alunos, permitindo que ocorra um desenvolvimento de modo prático, que nem sempre ocorre nos bancos escolares em salas de aula com formas de trabalho tradicional, nas quais 0 professor "passa a matéria" nos quadros ou nos slides de Datashow.

O presente estudo ocorreu em um Curso de Tecnologia em Análise e Desenvolvimento de Sistemas, presencial, na disciplina de Introdução à Computação ministrada a distância, no primeiro semestre do ano de 2018. Nesta, os alunos inicialmente quase não participavam da ferramenta fórum. Os alunos não se sentiam motivados e havia falta de engajamento.

Realiza-se um trabalho de pesquisa-ação para verificar o motivo da falta de participação dos alunos no fórum que era pontuado com uma porcentagem de $5 \%$, que era considerada relativamente pequena em relação a média bimestral. Por meio das reuniões entre professor (que era tutor da disciplina) e de 29 alunos da turma. Este que também era programador e desenvolvedor de websites e sistemas procurou ouvir os alunos e anotar suas queixas e coletando os dados.

Por meio de sua experiência, o professor tutor procurou atender os alunos e houve a proposta de algumas medidas: reprogramou o ambiente virtual para aceitar postagem no formato HTML e não no modo texto simples como estava configurado anteriormente, a seguir, fixou que tanto o professor como cada aluno utilizariam sempre uma cor, um tipo de letra e um tamanho de letra 
diferenciados para participação forense, de modo a permitir a rápida identificação de quem estava postando.

O professor tutor também configurou a permissão para que os alunos postassem vídeos em situações típicas do trabalho com computação conforme o desenvolvimento da disciplina: surgiram vídeos mostrando componentes do computador, desmontagem e montagem, configuração de recursos, instalação de placas especiais de vídeo para jogos, usos de softwares aplicativos e suas particularidades como é o caso da elaboração de índices em editores de texto e de tabelas dinâmicas no software de planilha. Elaboração e postagem de slides de software de apresentação etc.

A grande maioria dos alunos passou a participar e elogiar a nova forma de trabalho e houve a coleta de dados das afirmações dos alunos no final do semestre na época da conclusão da disciplina. As amostras de enunciados foram analisadas por meio da Análise do Discurso segundo a Escola Francesa considerando-se Pecheux (2011) que se utiliza do contexto para entender o sentido de algum enunciado e buscar a compreensão do fenômeno em foco. Considerando o respeito ao pedido dos participantes do estudo e às questões éticas, evitou-se citar localidades e nomes dos envolvidos.

\section{RESULTADOS E DISCUSSÃO}

Amostra de declarações coletadas início do semestre. Neste período o modo de trabalho do tutor para com os alunos era o tradicional com pouca interatividade e com um ambiente o mais simples possível que não possuía muitos recursos.

Amostra 1 (Aluno)

Enunciado: Não participo do fórum porque acho que ele não é interessante. Por exemplo, a gente nem sabe direito qual postagem é a do tutor e qual é dos colegas. Tem vários alunos querendo desistir do curso.

Análise: Observa-se claramente que há falta de motivação no aluno e da turma. Como considera Campos (2014) a motivação é uma força interna que surge nas pessoas como resultado de forças ou ações externas. Estas são criadas no ambiente que no caos é o AVA e suas ferramentas e cabe ao tutor e demais membros da equipe de EAD como é o caso do Designer Instrucional e do professor conteudista procurar torná-la mais interessante e atrativa ao aluno. Um ambiente mais interessante pode ser mais atrativo ao estudante da modalidade. Como os resultados nas ferramentas EAD dependem da qualidade da participação dos atores, de modo semelhante ao apresentado por Shitsuka e Shitsuka (2015), tornase necessário que esta participação seja melhorada e nada melhor que ouvir os alunos em suas sugestões para que ao atende-las estes se sintam respeitados, gostem do curso e não ocorra a evasão.

Amostra 2 (aluno)

Enunciado: Acho que a disciplina está muito teórica: o professor tutor posta as apostilas e faz perguntas no fórum e quer que os alunos respondam e nem corrige ou comenta e com isso, não sabemos se acertamos ou erramos.

Análise: Muitas vezes, os professores da educação tradicional vêm para a EAD e trazem seus modelos de trabalho tradicionais que nem sempre funciona nesta modalidade que exige a participação ativa do aluno. Segundo Silva, Shitsuka e Paschoal (2014) a participação de modo afetivo, que pode ser manifestada por meio da dialogicidade ou do diálogo entre os atores na ferramenta forense pode se constituir em um incentivo externo e que pode gerar a motivação. Esta situação pode ser considerada como a dos incentivos externos afirmada por Campos (2014) e pode ajudar a melhorar a participação e engajamento dos alunos no curso. Outra forma de trabalho do tutor que pode gerar incentivos é por meio do que os autores Tenório, Costa e Tenório (2016) consideram como sendo importante que a forma de atuação empática por parte do tutor pode se constituir em um incentivo para que os alunos de educação a distância se envolvam. Considerando os parâmetros mencionados e trabalhando-os em disciplinas EAD podem-se favorecer a obtenção de melhores resultados.

Amostra 3 (aluno)

Enunciado: Acho a disciplina muito parada. Os colegas têm de ler a apostila e participar de um fórum que acho que o tutor e os colegas poderiam ajudar comentando se o que postamos está correto ou se precisamos melhorar e aí teríamos a chance de aprender mais. 
Análise: Brasil (2016) exige por meio da Portaria $\mathrm{n}$. 1134 de 2016 que a IES que for oferecer disciplinas a distância no curso presencial tenha a infraestrutura e recursos necessários para realizá-la. Para Ferreira e Silva (2009) é necessário que ele supere o desafio 7 de estudar sozinho. Ocorre que as ferramentas são "frias" e nem todos os alunos se adaptam à falta de contato com outras pessoas e a falta de incentivos. Netto, Guidotti e Santos (2012) consideram que uma das causas importantes de evasão na EAD é a falta de adaptação ao método dessa modalidade que exige o "aprender a estudar sozinho". Neste ponto, a função do tutor torna-se de importância primordial para que não se perca o aluno. Segundo Shitsuka, Shitsuka e Boghi (2018) é importante que o tutor identifique as dificuldades e procure realizar as atividades de modo a recuperar $\mathrm{o}$ aluno. $\mathrm{O}$ olhar atento do tutor pode ser apoiado por meio da metodologia da pesquisa-ação que ajuda a identificar problemas e soluções que atendam a todos envolvidos uma vez que isso é feito de modo participativo.

Logo após a reunião, o tutor e equipe de $E A D$ procuraram implementar as sugestões feitas pelos alunos. Como estas foram realizadas de modo rápido logo no início do semestre, foi possível observar as mudanças que geraram satisfação e sucesso na grande maioria dos alunos. As notas do segundo bimestre aumentaram em relação as do primeiro bimestre. Houve aumento no engajamento dos alunos e apresenta-se a seguir a amostra de declarações coletadas no final do semestre.

Amostra 4 (aluno)

Enunciado: Todos gostaram da disciplina de Introdução a Computação. A gente conheceu mais os colegas, aprendemos uns com os outros e achamos que foi melhor que se a disciplina acontecesse presencialmente.

Análise: Verifica-se que ao invés da individualidade observada no início da disciplina, o trabalho coletivo, participativo e colaborativo fez com que todos se unissem criando um sentimento de pertencimento como consideram Palloff e Pratt (2002), ou seja, desenvolveu-se uma comunidade virtual. $O$ aluno considera que houve aprendizado coletivo e isso vai ao encontro das colocações de Vygotsky (2008) que considera importante o aprendizado histórico social e Silva, Shitsuka e Paschoal (2014) a afetividade nas participações que fez com que houvesse o sentimento de aceitação ao grupo incentivado pelo tutor de modo semelhante ao trabalhado por Tenório, Costa e Tenório (2016) que consideram que a forma de atuação empática por parte do tutor pode incentivar o aluno a participar e desenvolver o sentimento de pertencimento considerado por Palloff e Pratt, já mencionados anteriormente.

Amostra 5 (aluno)

Enunciado: Eu e os amigos estamos satisfeitos com a disciplina e acreditamos mais na EAD. Fizemos vários vídeos nos quais apresentamos situações profissionais, instalações de hardware e software e todos aprendemos em conjunto.

Análise: Observa-se o termo "amigos" que nos leva a pensar que houve um aumento de interatividade entre todos e isso pode ter levado ao surgimento da amizade entre os cursistas. Há um ponto de inflexão: tudo leva a crer que os alunos anteriormente ao trabalho de pesquisa-ação, não estavam acreditando nas disciplinas EAD e por meio das mudanças ocorridas passam a acreditar no sistema. A pesquisa-ação como considera Thiollent (2014), ao que tudo leva a crer, desempenhou um papel fundamental nas mudanças ocorridas e que podem ser diferentes em cada turma e em períodos diferentes. Torna-se interessante que o tutor seja uma pessoa bem preparada para lidar com os ambientes em mudança dos tempos atuais.

Amostra 6 (aluno)

Enunciado: Ninguém desistiu do curso. Todos ficaram felizes com as modificações feitas na disciplina. Quando começamos a participar do fórum com letras diferentes e pudemos nos expor mais, tendo as respostas dos colegas aprendemos muito mais.

Análise: Um dos aspectos que chama a atenção é o fato do tutor ter boa formação na área do curso e pelo fato de ser conhecedor da realidade dos profissionais de informática, passa a trabalhar de modo a atendê-los. Risemberg, Shitsuka e Tavares (2015) encontraram diferenças entre as formas de participação em ferramentas de AVA em turmas de Administração, Pedagogia e Tecnologia, sendo que os que menos participavam eram os alunos de 
tecnologia. Ocorre que ao ter um tutor da área de conhecimento do curso há uma identificação maior do tutor com as necessidades de aprendizagem da turma. Quando o tutor reconfigura o fórum do AVA para que aceite postagens no formato HTML, este passa ir ao encontro do interesse de aprendizado dos alunos. Também o emprego dos vídeos elaborados pelos alunos torna-se um atrativo uma vez que cada um pode mostrar alguma coisa que sabe da sua experiência profissional e/ou acadêmica ou dos cotidianos e com isso passa a ajudar os colegas a aprender mais. O uso de vídeos como considera Shitsuka e Shitsuka (2015) pode tornar o aprendizado mais atrativo, porém não garante a diminuição da evasão. Uma das possibilidades relacionadas com a diminuição da evasão mencionada pelo aluno pode ser por meio da atuação do tutor que passa ouvir mais e dialogar com os alunos, possivelmente, até atuando de modo semelhante ao que consideram Boghi, Shitsuka e Shitsuka (2019) em relação ao emprego de terapias alternativas melhorando o desempenho de alunos que passam a se organizar melhor para prosseguir em seus cursos.

Amostra 7 (Professor tutor)

Enunciado: Tive muita sorte com esta turma. Gosto da Tecnologia de Informação e de ensinar e acho que este pode ter sido um fator importante para o sucesso neste trabalho de tutoria.

Análise: Este tutor trabalhou bem e foi ao encontro do que determina Brasil (2016) que exige que se tenha além da infraestrutura, a forma de trabalho e o tutor. Neste caso, os trabalhos com a pesquisaação levaram ao sucesso do curso, porém este fato pode não ocorrer em todos os casos uma vez que os ambientes virtuais e suas ferramentas são altamente dependentes da qualidade da participação dos atores como considera Shitsuka e Shitsuka (2015) e desta forma, cada caso é um caso e o que se pode fazer é tentar criar condições favoráveis para que o sucesso aconteça.

\section{CONSIDERAÇÕES FINAIS}

O presente artigo traz a contribuição para alunos, tutores e instituições mostrando que é possível melhorar esta modalidade educacional por meio da pesquisa-ação participativa e do emprego de recursos que incentivem os estudantes a participar das ferramentas virtuais. Considera-se que cada turma é diferente e pode possuir formas diferentes de motivação.

Neste artigo apresentou-se um estudo no qual os alunos da disciplina EAD de Introdução a Computação de um curso presencial de Análise e Desenvolvimento de Sistemas, apresentavam dificuldades de participação no fórum e de engajamento na disciplina e esta situação é transformada por meio da forma de trabalho do tutor.

Para que se alterasse a forma de trabalho do tutor, realizaram-se reuniões entre alunos e tutor nas quais esses apresentaram suas dificuldades e o motivo da pouca participação nas ferramentas do AVA, em particular nos fóruns da disciplina, bem como de modo participativo e colaborativo, buscaram-se soluções para modificar a realidade para uma situação melhor.

O trabalho de pesquisa-ação tem a característica de envolver os participantes que vão realizar uma reflexão sobre suas dificuldades e propor mudanças que sejam factíveis. Esta metodologia foi desenvolvida por Thiollent e aplicada em vários ambientes, sendo que neste estudo, aplicou-se em uma disciplina a distância de um curso presencial. Por meio deste trabalho foi proposto que o tutor modificaria o ambiente virtual permitindo a postagem forense, ao invés do modo texto, para o modo HTML e ensinaria os comandos para que cada um trabalhasse com uma cor, tamanho e tipo de letra diferentes. A padronização da participação permitia a identificação rápida da postagem do tutor que seria em cor vermelha e letra Comic Sans, número 12. Observase que o HTML é uma linguagem de hipertexto utilizada para o desenvolvimento de websites e que possui comandos que permitem fazer a inserção de recursos como é o caso de vídeos e imagens bem como o emprego de letras, de tipos, tamanhos e cores diferentes.

Outras modificações envolveram o trabalho do tutor com respostas ou comentários às postagens dos alunos de modo mais rápido em no máximo 24 horas bem como a introdução de vídeos dos alunos produzidos pelos alunos e valendo nota, mostrando várias situações de trabalho da computação na disciplina, de modo a permitir aos alunos enxergar como se identificam os tipos de computadores, os componentes dos computadores, os tipos e componentes das redes de computadores, as configurações dos computadores e redes, a instalação, configuração e uso dos principais 
softwares do mercado. Dessa forma, a disciplina EAD ganhou formas dinâmicas, atrativas para os alunos que passaram a elogiá-la e participar ativamente do fórum e das atividades.

Sendo uma modalidade educacional importante, em crescimento e em quantidade de matriculas e cursos, bem como na educação presencial em instituições de ensino superior brasileiras, sugere-se que se realizem mais estudos sobre o assunto e que permita fazer uma base de conhecimento para os interessados na $E A D$ e uma das formas de se buscar o trabalho direto com alunos e tutores é por meio da pesquisa-ação que podem ser trabalhados em diversos cursos e situações que podem enriquecer o saber do leitor e por conseguinte da educação brasileira.

\section{REFERÊNCIAS}

BOGHI, Cláudio; SHITSUKA, Ricardo; SHITSUKA, Dorlivete M. Um estudo da possibilidade da minimização da evasão na educação a distância apoiada por terapia alternativa. Research, Society and Development. v. 8, n. 1, p.1-15. 2019. DOI: http://dx.doi.org/10.33448/rsdv8i1.567.

BRASIL. Portaria n. 1134, de 10 de outubro de 2016. Revoga a Portaria MEC $n^{\circ} 4.059$, de 10 de dezembro de 2004, e estabelece nova redação para o tema.

BRASIL. Portaria n. 1.428, de 28 de dezembro de 2018. Dispõe sobre a oferta, por Instituições de Educação Superior - IES, de disciplinas na modalidade a distância em cursos de graduação presencial.

CAMPOS, D. M. S. Psicologia da aprendizagem. Petrópolis: Vozes, 2014.

FERREIRA, R. B. A. S.; SILVA, I. M. M. "Didática" no contexto da educação a distância: quais os desafios? RBAAD - Revista Brasileira de Aprendizagem Aberta e a Distância. (Associação Brasileira de educação a distância ABED), São Paulo, v. 8, n. 1, p.1-14. 2009. Disponível em: http://www.abed.org.br/revistacientifica/ Revista_PDF_Doc/2009/DIDATICA_NO_CONTEXTO_ DA_EDCUACAO_A_DISTANCIA_QUAIS_OS_ DESAFIOSraad2010.pdf. Acesso em: 11 abr. 2019.

LUKDE, M.; ANDRE, M. E. D. A. Pesquisas em educação: uma abordagem qualitativa. 2.ed. São Paulo: EPU, 2013.

MIRSHAWKA, V.; MIRSHAWKA Jr., V. O boom da educação. São Paulo: DVS, 2002.

NETTO, C.; GUIDOTTI, V.; SANTOS, P. K. A evasão na EAD: investigando causas, propondo estratégias. In: I CLABES - Segunda Conferencia Latinoamericana sobre elAbandono de la Educación Superior, Pontificia Universidade Católica Rio Grande do Sul (Brasil) los días 8 y 9 de noviembre de 2012. Disponível em: http://www. alfaguia.org/www-alfa/images/ponencias/clabesII/LT_1/ ponencia_completa_26.pdf. Acesso em: 10 abr. 2019.

PALLOFF, R. M.; PRATT, K. Construindo comunidades de aprendizagem do ciberespaço. Porto Alegre: Artmed, 2002.

PEREIRA, A. S.; SHITSUKA, D. M.; PARREIRA, F. J.; SHITSUKA, R. Metodologia da pesquisa científica. Santa Maria/RS: UAB/NTE/UFSM, 2018. Disponível em: https://repositorio.ufsm.br/bitstream/handle/1/15824/ Lic_Computacao_Metodologia-Pesquisa-Cientifica. pdf?sequence=1. Acesso em: 11 abr. 2019.

RISEMBERG, Rabbith I. C. S.; SHITSUKA, Ricardo; TAVARES, Orivaldo de L. Un Estudio de Caso de Reconocimiento de Patrones en los Textos Colectivos en el Ciberespacio Mediante la Herramienta Wiki en Cursos a Distancia de Pregrad. Dialogos de la Comunicacion. Felafacs. v. 91, n.2. 2015. Disponivel em: http://dialogosfelafacs.net/wp-content/ uploads/2015/09/Dialogos91_UN_ESTUDIO_DE_ CASO_DE_RECONOCIMIENTO_DE_PATRONES_ EN_LOS_TEXTOS-.pdf. Acesso em: 10 abr. 2019.

SEVERINO, Antonio J. Metodologia do trabalho científico. 24. ed. São Paulo: Cortez. 2016.

SHITSUKA, R.; SHITSUKA, D. M.; BOGHI, C. Pesquisaação na Superação de Dificuldades de Acompanhamento de Curso de Pós-graduação a "Lato Sensu" a Distância por meio de Apoio da Tutoria. Rev. Bras. Aprend. Aberta e a Distância da ABED. v. 17, n. 1, 2018. Disponível em: http://seer.abed.net.br/index.php/RBAAD/article/ view/71. Acesso em: 11 abr. 2019. 
SHITSUKA, Ricardo; SHITSUKA, Dorlivete M. Formação de tutores para atuar na disciplina de LIBRAS em um curso de graduação a distância: um estudo de caso. Paidea - Revista Ciêntifica de Educação a Distância. v. 10, n. 17, jan. 2018. Disponível em. http://periodicos. unimesvirtual.com.br/index. php?journal=paideia\&page $=$ article\&op=view\&path[]=807\&path[]=714. Acesso em: 10 abr. 2019.

SILVA, Priscilla C. D.; SHITSUKA, Ricardo; PASCHOAL, Patrícia A. G. Afetividade nas interações em AVA: um estudo sobre a interação na educação a distância. RBAAD da ABED, v. 14, n. 1, p.12-20. 2014. Disponível em: http://www.abed.org.br/revistacientifica/_ Brazilian/2015/01_AFETIVIDADE_NAS_INTERACOES. pdf. Acesso em: 09 abr. 2019.

TENÓRIO, André; COSTA, Maria de F. A. C.; TENORIO, Thaís. A influência da empatia como competência socioafetiva na atuação de tutores a distância. RBAAD da ABED, v. 15, n. 1, p.11-22, 2016. Disponível em: http:// www.abed.org.br/revistacientifica/_Brazilian/2016/01_ Influencia_da_competencia.pdf. Acesso em: 10 abr. 2019.

THIOLLENT, M. Metodologia da pesquisa-ação. São Paulo: Cortez, 2011.

ZAMLUTTI, Maria E. M. Uma análise do surgimento da educação a distância no contexto sóciopolítico brasileiro do final da década de $\mathbf{3 0}$ e início da década de 40. Tese (Doutorado) Universidade Estadual de Campinas - UNICAMP - Campinas, SP, 2006. 